\title{
Re-Education: What Can Complementary and Alternative Approaches to Movement Education Teach Kinesiology?
}

\author{
David I. Anderson
}

\begin{abstract}
The goal of this special issue of Kinesiology Review is to expose kinesiology to a body of knowledge that is unfamiliar to most in the field. That body of knowledge is broad, deep, rich, and enduring. In addition, it brings with it a skill set that could be extremely helpful to professional practice, whether in teaching, coaching, training, health work, or rehabilitation. The body of knowledge and skills comes from a loosely defined field of study I have referred to as "complementary and alternative approaches to movement education" (CAAME). The field of CAAME is as diverse as the field of kinesiology. This introductory article focuses on what the field of CAAME has to teach kinesiology and what the field could learn from kinesiology. The overarching aim of the special issue is to foster dialogue and collaboration between students and scholars of kinesiology and practitioners of CAAME.
\end{abstract}

Keywords: Alexander technique, conscious awareness, Feldenkrais, Hanna somatics, ideomotor, kinesthetic, somaesthetics

But there are also unknown unknowns-the ones we don't know we don't know. (Donald Rumsfeld, Pentagon news briefing, February 2002)

\section{Aims of the Special Issue}

Kinesiology is an incredibly diverse field of study. It draws its content from the physical sciences, the life sciences, the social sciences, and the humanities. Because movement is fundamental to human existence, its content has practical relevance for virtually every aspect of human life. Kinesiology is still a relatively young discipline, even though the foundation of its content knowledge is as old as history itself. The American Kinesiology Association (AKA) outlined the basic knowledge and skills a graduate from a kinesiology program should have acquired during their course of study in 2014 (Chodzko-Zajko, 2014). Not surprisingly, that body of knowledge and those skills are broad. However, the requisite knowledge and skills a kinesiology graduate should possess is not without gaps, nor is it universally agreed on, particularly in terms of what knowledge and skills programs should emphasize.

Of the four core kinesiology content requirements-physical activity in health, wellness, and quality of life; scientific foundations of physical activity; cultural, historical, and philosophical dimensions of physical activity; and the practice of physical activity - the former two appear to be valued more than the latter two. Many have argued that the overemphasis on theoretical and scientific knowledge in kinesiology is an unfortunate consequence of Franklin Henry's (1964) push to model the discipline of physical education, the forerunner to kinesiology, on the science and mathematics disciplines, rather than on professional practice, to achieve academic legitimacy (e.g., Anderson, 2002, 2012; Johnson \& Twietmeyer, 2018; Newell, 1990). No doubt Henry's (1964) legacy has been a major contributor to what some consider the

The author (danders@sfsu.edu) is with the Marian Wright Edelman Institute for the Study of Children, Youth and Families, San Francisco State University, San Francisco, CA, USA. marginalization of the humanistic perspective on the study of physical activity, although that marginalization is complex and can be attributed to a range of causes (e.g., Twietmeyer \& Johnson, 2019).

The undervaluing of the cultural, historical, and philosophical dimensions of physical activity and the practice of physical activity create potential gaps in the knowledge and skill bases of kinesiology graduates. They are not the only gaps. Despite the breadth of the discipline of kinesiology, there remain bodies of knowledge with which students and scholars of kinesiology are largely unfamiliar. Moreover, there are skill sets that most students and scholars never acquire, despite their personal and professional relevance, particularly for those interested in personal development, rehabilitation, or peak performance. To paraphrase Donald Rumsfeld's quote at the start of this article, "We don't know what we don't know."

\section{A Gap in Our Understanding of Human Physical Activity}

A primary aim of this special issue is to shed light on a body of knowledge and skill set most scholars in kinesiology don't know they don't know- to draw attention to another gap in our understanding of human physical activity. That body of knowledge and skill set is connected to what I have labeled "complementary and alternative approaches to movement education" (CAAME), for want of a better label. Though unwieldy, particularly because it is plural ("approaches") rather than singular, I chose the label for two reasons. First, it aligns with the National Institute of Health's National Center for Complementary and Integrative Health (NCCIH), which categorizes the approaches that are the focus of this special issue as "mind and body" practices. I prefer not to use the NCCIH label because it reifies a false dichotomy between mind and body. The NCCIH's website lists the most popular of these practices as yoga, chiropractic and osteopathic manipulation, and meditation. Others they list include acupuncture, relaxation techniques, tai chi, qi gong, hypnotherapy, Feldenkrais method, Alexander technique, Pilates, Rolfing structural integration, and Trager psychophysical integration. Many other practices are not listed. 
Practitioners and theorists have used the label "bodywork" to collectively refer to the approaches recognized by $\mathrm{NCCIH}$ (e.g., Juhan, 2003), while acknowledging that the label fails to do justice to their breadth and complexity. Attempts have been made to unify the approaches into a scientific field of study. The most notable was by Thomas Hanna, who coined the term "somatics" in 1976 (after using the term "soma" to designate the experienced body in contrast to the objectified body, e.g., Hanna, 1970) when he founded the Somatics Magazine: Journal of the Bodily Arts and Sciences. The field of somatics could be described as the study of the human body through a personal experiential perspective; although consistent with F.M. Alexander's preferred terminology (e.g., Alexander, 1932), it would more appropriately be described as the study of the "self" from a personal experiential perspective. From my vantage, the somatics label does not fully reflect the integrated nature of mind-body, although the label "somaesthetics" (e.g., Shusterman, this issue) would appear to capture that integration more saliently.

The second reason for using the label "CAAME" is to highlight that the approaches covered in this special issue are educational, rather than therapeutic. The educational component is evident in the active participation of the student in the acquisition of a skill that can be deployed in any aspect of life, ranging from personal development, to prevention or remediation of injury, to the attainment of peak performance. Many approaches, which might better fit under the bodywork label, are not covered in the special issue because they are primarily therapeutic and the student, who is really a client or patient in this case, is generally passive. In other words, the practitioner does something to them. The patient does not necessarily learn anything that can be used to prevent a recurrence of the problem for which help was sought in the first place or that can be applied to improve other aspects of life. The omission of these approaches is not meant to downplay their efficacy. Some of the approaches have impressive success in dealing with a range of maladies.

\section{Self-Knowledge Is Undervalued by the Academy}

A secondary aim of the special issue is to highlight how much the academy has undervalued self-knowledge. It is quite bizarre that we expect students to graduate with broad and sometimes deep knowledge of the world around them and yet we care little about whether they have learned anything useful or interesting about themselves. Students are expected to be able to think critically, reflect, and reason, but not about themselves. It is surprising that the educational objectives of most institutions of higher education fail to mention the importance of developing self-knowledge. The importance of understanding the sensations that arise from our own bodies is entirely missing. Even AKA's learning outcome relative to the practice of physical activity seems lacking in that regard: "A Kinesiology graduate will be able to . . . demonstrate an appreciation and commitment to physical activity practice" (American Kinesiology Association, 2020). Bainbridge Cohen (2012), an enthusiastic proponent of experiential anatomy and originator of a practice known as body-mind centering, provided an intriguing insight into the academy's undervaluing of selfknowledge and its relevance to kinesiology when she wrote,

As all sciences are reflections of the socio-political-religious ideas of their time, it is appropriate that the historical repression of bodily sensation in Western Culture has been transmitted as a matter of scientific fact. Within this view, a phenomenon is considered to be "objective scientific fact" if it can be separated from all bodily sensations, i.e., it must be capable of being measured only auditorily and/or visually. If it is measured by bodily sensation, it is considered to be "subjective" and "not scientific." The experience of movement is not considered to be "scientific study." . . . In universities throughout this country, in movement science programs, such as Motor Learning and Exercise Physiology, the actual movement has to be separated from all bodily sensation in order to be studied or validated. Most of these programs do not even offer movement classes. Movement is studied via reading and video. (p. 114)

As Bainbridge Cohen noted, in its desire to be as rigorous and objective as possible, science disparages knowledge that cannot be communicated in written or oral form and therefore passed down from one generation to the next. We privilege concrete and verifiable knowledge because it is the type of knowledge that flows logically from use of the scientific method. Juhan (2003) beautifully captured the paradox created by this scientific prejudice when he wrote,

Objectively verifiable, measurable observations are certainly the cornerstone of the physical sciences. They are serious inquiry's protection against fantasies, projections, prejudices, and chicanery. The only problem with relying upon them exclusively in the investigation of our bodies and minds is that in order to do so we must systematically ignore huge amounts of data, data that is tainted because it is merely "subjective." Thus we rid research of the "human"- that is, the unreliableelement. But when it is the human response that we wish to study, no amount of experimental sophistication can conceal the fact that it is the very things that would be most helpful to know which strict empiricism obliges us to disregard. (pp. xxvii-viii)

Science's desire to be rigorous and objective also downplays the importance of personal experience in the construction of knowledge and in all acts of understanding. For example, forward-thinking early-childhood educators and theorists like Montessori (1967) and Vygotsky (1978) consistently stressed the importance of hands-on experience with the environment in the development of the mind, and Piaget (1952) famously asserted that the origins of intelligence were in the child's own sensorimotor interactions with the world. Similarly, Sheets-Johnstone (1999) argued, "Movement is indeed the mother of all cognition" (p. xxi). The noted physical chemist turned philosopher Polanyi (1962, 1966) stressed that the scientist's personal participation in her knowledge is an indispensable part of science itself, insisting that "any attempt to rigorously eliminate our human perspective from our picture of the world must lead to absurdity" (1962, p. 3). The current literature on embodied cognition provides numerous examples of the contribution that physical activity and personal kinesthetic experience make to psychological functioning, psychological development, and academic performance (e.g., Kontra, Lyons, Fischer, \& Beilock, 2015; Thelen, 2000; Tomporowski \& Pesce, 2019; Wilson, 2002).

Heightened self-awareness is also critical to understanding our own biases and prejudices. These biases and prejudices can seriously impair our ability to evaluate new ideas and perspectives, an ability that is critical not only to the development of new knowledge but also to the maintenance and progress of civil society. In our currently highly racialized era, it is telling that 
some trauma specialists have argued that we can only hope to heal ourselves and our society from the trauma associated with Whitebody supremacy by beginning with a body-centered approach (e.g., Menakem, 2017).

\section{The Academy Undervalues Knowledge Generated Outside the Academy}

A third aim of the special issue, related closely to the first two objectives, is to highlight the value of knowledge generated outside of the academy. Sometimes we seem to think that scientific discoveries are only made by scientists and that learning only happens in schools and universities. This is clearly not the case as evidenced by the contributions in this issue. The two CAAME "pioneers" featured in this special issue, F.M. Alexander and Moshe Feldenkrais, made profound discoveries about human behavior by rigorously and systematically studying themselves and then applying their discoveries to the study of others. To argue that their discoveries are unimportant to kinesiology because they were not "scientists" would be equivalent to arguing that Bill Gates is not qualified to diagnose a problem with your computer because he does not have a degree in computing or engineering. Clearly, we should scrutinize discoveries made by people like Alexander and Feldenkrais with the same level of scientific curiosity and skepticism we bring to all information we encounter. I would ultimately like to see the ideas of Alexander, Feldenkrais, Hanna, and similar geniuses represented in the kinesiology curriculum. Their work is clearly worthy of study and should be interrogated rigorously.

\section{Dialogue Is Needed}

The final aim of the special issue is to encourage dialogue between scholars of kinesiology and practitioners of CAAME, among practitioners of CAAME themselves, and especially among the handful of people who have one foot planted in the world of academia and another in one or more of the subdisciplines in CAAME. The intent is not just to break down the walls between academia and the outside world but also to break down the barriers between the various CAAME disciplines, whose practitioners often operate in silos, oblivious that they have "kin" folk in related areas. ${ }^{1}$ There is much to be gained by all stakeholders by sharing ideas and showing an openness to each other's perspectives. By embracing differences, practitioners and scholars might come closer to understanding what is unique and what is universal in that which we collectively study.

\section{Scope of the Special Issue}

This special issue was deliberately limited to focus on the educational approaches developed by F.M. Alexander and Moshe Feldenkrais. Four reasons motivated this decision: (a) Alexander and Feldenkrais were pioneers, inspiring many others to develop their own methods; (b) their work is systematized and more widely recognized than most other approaches in the field; (c) their approaches are clearly educational (actually re-educational) rather than therapeutic; and (d) their work has been subjected to much greater scientific scrutiny than most other approaches. The work of Thomas Hanna is also featured because he did more than any other person to unify the various CAAME into a coherent field of study and his ideas have major implications for the future development of such a field of study. Contributions from contemporary scholars Richard Shusterman and Wolf Mehling are included because their work represents salient examples of current attempts to study the mind-body from a self-referential perspective. Shusterman has also written extensively about a unified field of study he has called somaesthetics. Finally, a contribution by Ezequiel Morsella and colleagues reminds us of the centrality of the study of human action to an understanding of one of science's most vexing problems- the emergence of consciousness. It is exciting to think that kinesiology might play a role in the understanding of consciousness and intriguing to think that such understanding might be facilitated by familiarity with the work developed by the likes of Alexander and Feldenkrais and those who have followed their leads.

Limiting the special issue to the current contributions does not do justice to the diversity of CAAME that currently exist. The origins of these approaches are ancient, although they proliferated in Western culture greatly during the twentieth century, fueled by the rising popularity of existentialism and phenomenology in philosophy and the growing influence of mind-body traditions and perspectives from the East, such as Eastern martial arts and yoga (Eddy, 2009). Philosophers and educational theorists like John Dewey and Maurice Merleau-Ponty also had a major influence on the acceptance of many of these approaches to movement education. ${ }^{2}$ Germany was the birthplace for many of the theories and practices that underpinned the early movement education pioneers. For example, Elsa Gindler (1885-1961) developed a school of movement education after using exploration of her body and self-observation of her breathing to recover from tuberculosis. She and her students explored simple everyday movements like sitting, standing, and walking. Another pioneer, Bess Mensendieck (1864-1957), developed a system of over 200 exercises for executing movement to improve habits and general functioning. These movements were often done in front of a mirror with minimal clothing.

Mabel Todd is another pioneer, though an American in this case, who had a major influence on the development of more contemporary systems of practice. After a paralyzing accident, Todd was told that she would never walk again. Refusing to accept the advice of her doctors, a common occurrence in the pioneers of CAAME, most of whom developed their methods in response to their own adversity, she developed a process of using imagery about the balanced use of the body to heal herself (see Todd, 1937, for examples). The system was later systematized by her student Lulu Sweigard into a method referred to as ideokinetic imagery (Sweigard, 1974). Todd is notable because she was a faculty member in the Department of Physical Education at Teachers College, Columbia University, where she taught anatomy, posture, and neuromuscular awareness to physical education and dance students. Thanks to the early pioneers, there were over 37 different somatic movement certification programs when Eddy (2009) wrote a brief history of somatic education and its relationship to dance.

Eastern perspectives on movement education are not included in the special issue, with the exception of a brief discussion of Tai Chi by Bradford Bennett, for the simple reason that these perspectives are so broad and diverse that it was difficult to find authors who could be said to represent the breadth and diversity of current approaches. Moreover, the literature on these approaches is enormous. For example, a Google Scholar search on "health benefits of yoga" reveals thousands of papers that have been published on this topic. The omission of yoga, in particular, is unfortunate given the enormous popularity of yoga classes among students who participate in the physical activity classes offered by departments of kinesiology. That popularity is telling because it reveals how receptive students are to nontraditional forms of physical activity, 
perhaps illuminating their potential interest in the ideas discussed in this special issue.

The final telling omission from the special issue is of an approach that has a developmental perspective, although it must be stated that Alexander and Feldenkrais worked with people of all ages, including very young children. The omission is not an indictment against current developmental approaches. Unfortunately, one developmentally focused contribution to the issue was derailed by COVID-19 and there was insufficient time to find a replacement. I hope the original contribution can be published in a forthcoming issue of Kinesiology Review. In the meantime, for those interested in a contemporary and popular developmental approach, I highly recommend reading Bainbridge Cohen's (2018) book on neurocellular patterns and developmental movement.

\section{What Does the Field of CAAME Have to Offer Kinesiology?}

\section{Reification of the Primacy of Movement}

The approaches to movement education featured in this special issue offer considerable value to the field of kinesiology. First and foremost, an understanding of these approaches would lead to an expansion of the knowledge and skill bases in kinesiology and it would reify the "primacy of movement," to borrow a phrase from Sheets-Johnstone (1999), that our field so often takes for granted. The centrality of movement in all human endeavor is a central feature of nearly all the CAAME, and it is a fact of life that the field of kinesiology does not promote vigorously enough. It is worth remembering what some of our most eminent scientists have said on this topic. For example, the renowned neuropsychologist, neurobiologist, and Nobel Laureate Roger Sperry famously stated that "the entire output of our thinking machine consists of nothing but patterns of motor coordination." (1952, pp. 297-298). He went on to state,

In the same way our finest deeds consist only of patterns of muscle-fiber twitches, our greatest printed passages only of ink marks on paper, and our most ravishing music, as pointed out by William James, is but the rasping of hairs from a horse's tail on the intestines of a cat. (p. 310)

Similarly, Sir Charles Sherrington (1951) affirmed how important movement has been for the evolution of our species:

As we look along the scale of life, whether in time or in order of organization, muscle is there before nerve, and nerve is there before mind, "recognizable mind." It would seem to be the motor act under "urge to live" which has been the cradle of mind. The motor act, mechanically integrating the individual, would seem to have started mind on its road to recognizability. (p. 161)

The idea of the motor act, or movement, serving as the binding force between what have traditionally, and mistakenly, been dichotomized as mind and body is central to the philosophies that underlie CAAME. As Todd (1937) reminds us, "The individual is a totality and cannot be segregated as to intellect, motor and social factors. They are all interrelated" (p. 3). How we move influences not just our health but our entire way of being in the world. This is a message we need to stress over and over again to our students, especially given the way that most departments of kinesiology currently compartmentalize the study of physical activity and then attempt to bind it back together with some type of culminating experience. The holistic nature of human structure and function and the importance of studying human behavior in context constitute a core feature of the contemporary dynamical systems and ecological approaches to the study of motor behavior (e.g., Davids, Button, \& Bennett, 2008; Kelso, 1995; Kugler \& Turvey, 1987; Stoffregen \& Bardy, 2001; Thelen \& Smith, 1994); however, the holistic and contextual perspective is by no means universal in the kinesiology curriculum.

\section{Another Perspective on the Practice of Physical Activity}

The issue of the primacy of movement has implications for the scope of what kinesiology studies relative to the practice of physical activity. Johnson and Twietmeyer (2018) recently argued that kinesiology needed a more specific definition of physical activity, one that focused on the long-standing tradition of participation in dance, exercise, games, play, and sport. I disagree with this idea. These arenas of participation are all important and worthy of study, but the primacy and ubiquity of movement suggest that there is no arena in human life that is off limits for the student and scholar of kinesiology. Movement literally pervades all aspects of our lives, and so the kinesiologist can find relevance in studying any activity. The field has just as much to teach the world about sitting, standing, speaking, keyboarding, or any one of a myriad of activities of daily living as it does about tumbling, dancing, swimming, playing games and sports and the like. Kinesiology should embrace the ubiquity of movement and see it as a strength of the field rather than something that dilutes our mission.

Related to the practice of physical activity is how kinesiology understands key concepts like physical (motor) competence and physical literacy. These concepts have multiple meanings in the field (e.g., Cairney, Kiez, Roetert, \& Kriellaars, 2019; Keegan et al., 2019; Shortt, Webster, Keegan, Egan, \& Brian, 2019). The CAAME offer another perspective on physical competence and literacy, one that is grounded in the notion that learning to move skillfully does not need to be coupled to the acquisition of proficiency on a specific task. Rather, the goal of many CAAME is to learn principles associated with skillful movement that can be deployed in the performance or learning of any task. An important premise behind this approach is that task-specific learning can lead to the development of habits that ultimately interfere with optimal functioning if it is undertaken before the general principles associated with skillful movement are understood. The premise has enormous implications for physical education because it suggests an educational approach in which learning the principles of skillful movement precedes the acquisition of specific movement patterns. This suggestion might be very difficult to comprehend for anyone who is unfamiliar with one of the CAAME. With that in mind, it is perhaps appropriate to finish this idea by noting that the philosophies at the heart of most CAAME are consistent with the "Whiteheadian" (Edwards, Bryant, Keegan, Morgan, \& Jones, 2017) view of physical literacy, which stresses the holistic, integrated, and embodied nature of human behavior (e.g., Durden-Myers, Meloche, \& Dhillon, 2020; Whitehead, 2001, 2013).

\section{Additional Tools to Address the Pandemics of Physical and Psychosocial Illness}

Another value of understanding CAAME is in addressing the pandemic of musculoskeletal problems (and the chronic pain 
associated with them) that has not been alleviated by conventional physical education or conventional medicine. ${ }^{3}$ The world is currently focused on the twin pandemics of COVID-19 and institutionalized racism. Like racism, the pandemic of musculoskeletal problems is not a new pandemic. It has been with us for a considerable time, likely exacerbated by an increasingly sedentary way of living. What accounts for this pandemic? Why has our educational system failed to prevent this pandemic and why have conventional treatments proved inadequate? Why do more than $30 \%$ of adults and approximately $12 \%$ of children seek help from health care approaches that are not typically part of conventional medical care or that have origins outside of usual Western practice (National Center for Complementary and Integrative Health, 2018)? The answers to these questions are complex, and space does not permit a detailed examination of them here. However, it is highly plausible that many of the musculoskeletal problems in existence today are connected to a compromised sense of posture and movement. Apart from the pain experienced, people have become numb to their bodies. Alexander (1918) originally described this problem as debauched kinaesthesia. Hanna (1988) referred to it as sensorimotor amnesia, and Myers (1998), while arguing that our generation is kinesthetically illiterate, has used the term "kinesthetic dystonia" to describe it. How this situation has manifested itself is another fascinating and complex story, one that is, again, beyond the scope of this article. Nevertheless, the approaches outlined in the special issue maintain that kinesthetic sensitivity can be re-educated and that such a re-educational process can have a significant ameliorative effect on a range of musculoskeletal complaints that stem from modern living. This idea is well worth exploring.

Like the pandemic of musculoskeletal problems, we have a pandemic that is psychosocial in nature, with persistent reports among people of all ages of anxiety, depression, isolation, and loneliness (Plakun, 2020). Although most scholars of kinesiology do not consider themselves counselors or psychotherapists, with the exception of some who work in clinical sport and exercise psychology, the field has much to offer in this area considering that movement is a force that integrates the mind-body. Attending mindfully to ourselves as we move, and noticing when and where we grip ourselves, can make a significant contribution to our psychosocial state, and thus it offers a potential antidote to the pandemic (Salmon, 2020). Again, this idea is well worth exploring. With respect to physical and psychosocial health, neuroscientific research has revealed the remarkable plasticity in the brain and body that enables recovery from a range of different debilitating conditions, often following nonconventional interventions (e.g., Doidge, 2015).

\section{Another Approach to Understanding and Achieving Peak Performance}

The value of CAAME is as evident in the attainment of peak performance as they are in the alleviation of the suffering associated with musculoskeletal and psychosocial problems. Nowhere is this more obvious than in the way these approaches have been embraced by those who study theater, dance, and music. It is not uncommon for departments of theater, dance, and music to employ specialist movement educators or to have their own movement education programs. This embrace, which has as much to do with the prevention of injury as it does with the promotion of peak performance, should be a wake-up call for kinesiology. Our field has much to contribute to the performing arts. Similarly, our field has much to gain by understanding some of the methodologies that are used to develop expertise in the activities central to the performing arts.

\section{Insights Into Unconscious Bias}

Would our science and pedagogy be better if we embraced approaches that encouraged us to examine our own personal biases more critically? Do we show blind adherence to our theories and our pedagogical practices because our sense of self is dull? I believe that the answer to these questions is an unequivocal yes. Our bias toward teaching concrete, objective facts that can be transmitted to students verbally or in writing has led to an undervaluing of the role our movements and their attendant kinesthetic consequences can make to understanding the information and concepts with which we grapple (see the earlier section "Self-Knowledge Is Undervalued by the Academy"). As Polanyi (1966) pointed out, we shape all knowledge by the way we know it. Much can be gained from adopting pedagogical practices that engage our kinesthetic sense, not simply because of the contribution such practices make to the development of self-knowledge but also because of the contribution they make to understanding the world around us. Moving is a way of knowing. Learning that engages the kinesthetic sense develops kinesthetically literate students, and such students are not only more rounded but also likely to have a deeper understanding of their subject matter. Why, for example, is an experiential anatomy class not required in our curricula? An experiential anatomy class would seem to be a logical (and ideal) way to "bring to life" the complexity of the human body and facilitate an appreciation and understanding of that complexity. The teaching of anatomy is not the only subject that could benefit from kinesthetically based experiential learning (e.g., Kontra et al., 2015).

\section{Further Development of Theory}

Theory development could also profit from incorporation of ideas from CAAME. Kuhn (1970), in his treatise on the structure of scientific revolutions, maintained that paradigm shifts in the scientific disciplines often occur when new generations of scholars import into their fields ideas and concepts that are already well developed in other, previously unrelated, fields of science. In kinesiology, for example, Abernethy and Sparrow (1992) note that the introduction of concepts from chaos theory and thermodynamics to the study of movement control had a major influence on the development of the dynamical systems paradigm in motor control and learning. What might we learn by cross-fertilizing our fields of study in kinesiology with some of the insights gained by the theorists and practitioners from CAAME (Thelen, 2005 provides a potential preview)? Will new paradigms emerge? Will new insights be gained into long-standing problems in the field? Again, I would say that the answer to these questions is an unequivocal yes. The discoveries made by the likes of Alexander, Feldenkrais, and Hanna were profound, even if barely known. They were brilliant individuals, like so many others working in this field of study.

\section{Alternative Career Opportunities}

The final benefit to kinesiology of embracing the CAAME is the potential to open up new career opportunities. This benefit is proffered cautiously and with a certain reticence. Just as it is difficult to make a living as a personal trainer, it is perhaps 
even more difficult to make a living as a movement educator. This is particularly true given that movement educators are not the beneficiaries of subsidies or reimbursements from governments or insurance companies (at least, not yet), which constrains the potential clientele base considerably. Knowledge and skill are not sufficient to succeed in this profession. Successful practitioners are those who combine their knowledge and skill with grit, determination, resilience, a strong work ethic, and an entrepreneurial acumen. Nevertheless, some practitioners do develop thriving practices. There is another way to look at career opportunities, however. Rather than seek a career as a practitioner of a particular method, students should consider how the knowledge and skill they can develop in one or more of the CAAME might enhance their practice in another profession like teaching, coaching, physical therapy, occupational therapy, nursing, or another allied health profession. The skills that can be developed in this area can complement practice in nearly any profession, allowing a student to distinguish her- or himself from her or his peers, in addition to the significant contribution these skills can make to personal development.

\section{Another Pool of Students}

The popularity of nontraditional physical activity classes (e.g., Tai Chi and yoga) offered by kinesiology programs suggests that university campuses have a pool of students, not necessarily in departments of kinesiology, willing to embrace the ideas that underpin the CAAME. What students who sample these nontraditional activity classes lack is a broader framework to which they can link their experience and within which they can understand it. An embrace of the CAAME by departments of kinesiology could ensure that the rapid growth experienced by the field of kinesiology in the academy will continue well into the future.

In summary, kinesiology stands to gain considerably by sampling and understanding the CAAME. What one can learn from these approaches can have a profound effect on personal development and professional practice, regardless of the area within kinesiology in which one works. The potential to forge collaborations with practitioners of the CAAME offers many opportunities to address pressing societal problems, only some of which have been targets for work in kinesiology. The potential to improve pedagogy, develop new paradigms, build theory, and grow our field is significant. In addition, the opportunities to enrich our research and scholarship are abundant. The CAAME offer an incredibly fertile area for future research.

\section{Why Should Practitioners of CAAME Embrace Kinesiology?}

\section{Professional Legitimacy}

An affiliation with the field of kinesiology potentially offers practitioners of the CAAME significant benefits. Chief among them is access to the broad scientific knowledge and skill bases that underpin kinesiology-bases that offer a comprehensive understanding of how behavior is organized and learned, how ideas are systematically tested, and how practice might be improved. These knowledge and skill bases are potentially critical to the professional acceptance and legitimacy on which practitioners' work depends. It is important to note here that the National Research Council officially recognized kinesiology as a legitimate academic discipline in 2006 (Thomas et al., 2007), and the field has grown significantly since that recognition. Given the way that society privileges knowledge derived from the scientific method and the written and spoken word, practitioners can gain legitimacy by explaining their methodology relative to our current scientific understanding of the mind, brain, body, and behavior (though I reluctantly list these as if they were disconnected elements of the self). Science already has a wealth of information about anatomy, physiology, psychology, and sociology that can inform practice. Moreover, it is instructive to learn how one's personal practice and philosophy might be represented in existing philosophies of thought.

Practitioners of the CAAME also need to understand that many of their approaches already have an impressive body of scientific evidence supporting their efficacy. The record of success is often as impressive as that of favored conventional approaches to personal development, performance enhancement, or treatment of specific problems, although it is critical to understand the scientific method in order to distinguish credible from implausible research claims. An appropriate balance of scientifically accurate factual and conceptual knowledge and personal knowledge is a key to professional credibility.

\section{Enhanced Understanding of the Uniqueness and Universality of Approaches}

Another benefit of an affiliation with kinesiology, thanks to the breadth of knowledge students are encouraged to acquire, is a deeper appreciation for the connections among the many CAAME that currently exist. Such an appreciation could lead to a breaking down of the silos within which many practitioners operate and a deeper understanding of the historical roots and philosophies that underlie the specific methods they deploy during their work. My experience has been that many practitioners "borrow" techniques from approaches other than the one in which they were trained without necessarily realizing that the techniques came from elsewhere, or even that they are not part of the "toolkit" in their own specific approach. As Eddy (2009) noted, there are dozens of CAAME thanks to the bifurcation of techniques and amalgamation of ideas over many decades. There appear to be few purists anymore, although purists also stand to gain from a greater familiarity with other approaches. Oftentimes, practitioners are not even aware that alternative approaches exist-such is the process by which so many practitioners are exposed to their approach. When asked how their approach differs from another approach a prospective student might have sampled, they do not have an answer. A broader understanding of the field of CAAME, such as might be experienced in a kinesiology curriculum, would potentially offer practitioners insight into what is unique about their approach but also what is universal across approaches. Moreover, just as paradigm shifts are likely to occur in any scientific discipline by importing ideas from other fields, paradigm shifts that significantly enhance the field of CAAME might ensue from practitioners crossing and sampling each other's work. I believe that this will be essential for the discovery of new approaches and refinements to existing approaches to improve their success.

\section{Expanded Reach}

A final benefit to the practitioner is an expansion of reach. Over 2 decades ago, Myers (1998) lamented that while the therapeutic value of bodywork and movement therapies, as he labeled them, was in the ascendancy, simple math on the number of practitioners 
relative to the number of people who needed help suggested that it would take approximately 150 years just to help the people in the United States and Europe. He argued that practitioners needed to embrace their role as educators to meaningfully address the magnitude of the problem they were confronting, and he argued that a revision of physical education was needed. To quote Myers (1998) directly, "When a problem is that widespread, it is neither the medical system that we must fault, nor our own efforts, but the physical education system of our culture, taken in its entirety" (p. 113). I believe Myers's (1998) recommendation is as relevant today, and perhaps even more relevant, as it was over 20 years ago. Because of their basis in prevention rather than remediation of problems, CAAME could be at the forefront of a revolution in the way we approach physical education. Practitioners can make the most impactful and enduring contribution to society by focusing efforts on teaching people the principles of their work before those people actually need them. This requires a serious effort to find inroads into our educational system, and the field of kinesiology offers an ideal entry point.

\section{The Articles in This Issue}

The special issue comprises nine articles, including this introductory article, written by scholars who are deeply familiar with one or more of the CAAME. In the first article, Woods, Glover, and Woodman provide a lucid introduction to F.M. Alexander and the Alexander technique. They describe how the technique was developed, how it is practiced and learned, and the evidence for its effectiveness, ultimately showing how it can be applied to any and every situation a person encounters. The second article, by Cacciatore, Johnson, and Cohen, goes deeper into the process by which the Alexander technique works and the evidence base behind it. The authors present a novel and intriguing neurophysiological model of the potential mechanism that underlies Alexander's discovery-a model that is likely to generate considerable discussion and debate. In the third article, Russell provides comprehensive insight into Moshe Feldenkrais and his method. With many examples, he reveals the complexity inherent in the group and individual lessons that define the method and highlights the ontological and epistemological stances that make the method unique. In the following paper, Stephens and Hillier summarize the scientific evidence for the effectiveness of the Feldenkrais method and outline an agenda for future research. Notable in their paper is an enthusiastic call to collaborate with scholars who have an interest in following up on their proposals for future research.

The fifth article in the special issue, by Bennett, marks a shift toward synthesis. Bennett describes Thomas Hanna's contribution to the development of somatic education and somatics as a field of study. He describes the unique aspects of Hanna's techniques and the theories and philosophies that influenced their development, contrasting the techniques with those practiced in Tai Chi. He finishes with a discussion of the difficulties of conducting research on somatic education and some ideas about how kinesiology and somatic education can inform each other. In the sixth article of the issue, Shusterman describes an interdisciplinary research program referred to as somaesthetics. He distinguishes it from the specific methods of somatic practice and describes its philosophical roots, theory, practice, branches, and dimensions, as well as its potential convergence with kinesiology. He outlines how somaesthetics offers an overarching framework for integrating a variety of different discourses about the body and its lived experience into a coherent field of study. The next article in the issue, by Mehling, examines the issue of measuring changes in bodily awareness, a key characteristic and potential mechanism of action in most of the CAAME. He distinguishes between maladaptive and salutogenic forms of bodily awareness and overviews the efficacy of contemporary methods for capturing changes in the latter that might ensue from CAAME interventions.

In the final article of the special issue, Morsella and colleagues review psychological theories that illuminate how a special kind of action selection relates to the function of the conscious field. They discuss how the contents of consciousness collectively influence action selection-what we commonly know as voluntary behavior. Morsella et al. are not practitioners of any of the CAAME, and their paper may seem out of place in the special issue. However, I would argue that it is perhaps the most important paper in the group because it highlights the centrality of action and movement to the integrated nature of mind-body. According to Morsella and colleagues, if a conscious content is absent from the conscious field, it cannot influence the selection of actions from the skeletomuscular system. Consequently, the contents of conscious awareness have a direct influence on whether our behaviors are adaptive or maladaptive. This idea has profound implications for practitioners who seek to expand conscious awareness of the self and the relation between the self and environment to improve quality of life.

In summary, the articles in this special issue provide rich insights into a body of knowledge that most students and scholars of kinesiology know little about. I hope the articles in the issue will pique the curiosity of kinesiologists and practitioners of the CAAME alike. In addition, I hope they will encourage an appreciation of what the CAAME can offer kinesiology and what kinesiology can offer the CAAME. Moreover, I hope they will encourage dialogue and collaboration across the respective fields, within the CAAME and between the CAAME and kinesiology, such that we can share best practices and further a research agenda that has the potential to improve the quality of living for our current generation and generations to come.

\section{Notes}

1. Those of us in kinesiology know that the origin of the term "kinesiology" is in the Greek word for movement; however, Myers (1998) also notes that "kin" is generally defined as one's family and relations and thus suggests connections among people.

2. It is notable that Dewey wrote the introductions to the first three of Alexander's books. The noted philosopher and anatomist G.E. Coghill wrote the introduction to his fourth.

3. Because the musculoskeletal system is intimately related to the digestive, respiratory, and circulatory systems, musculoskeletal problems can have broad-ranging negative effects on these other systems. Conversely, the alleviation of musculoskeletal problems can have salutary effects on these systems. This is a premise behind many CAAME, although it has received scant empirical scrutiny.

\section{References}

Abernethy, B., \& Sparrow, W.A. (1992). The rise and fall of dominant paradigms in motor behavior research. In J.J. Summers (Ed.), Approaches to the study of motor control and learning (pp. 3-45). Amsterdam, the Netherlands: Elsevier. 
Alexander, F.M. (1918). Man's supreme inheritance: Conscious guidance and control in relation to human evolution. New York, NY: E.P. Dutton \& Co.

Alexander, F.M. (1932). The use of the self. London, UK: Methuen \& Co. American Kinesiology Association. (2020). Section two: Learning outcomes [Web page]. https://www.americankinesiology.org/SubPages/ Pages/Learning\%20Outcomes

Anderson, D.R. (2002). The humanity of movement or "It's not just a gym class," Quest, 54(2), 87-96. doi:10.1080/00336297.2002. 10491768

Anderson, D.R. (2012). The death of play in U.S. culture. Kinesiology Review, 1(1), 59-65. doi:10.1123/krj.1.1.59

Bainbridge Cohen, B. (2012). Sensing, feeling, and action: The experiential anatomy of Body-Mind Centering ${ }^{\circledR}$ (3rd ed.). Northampton, MA: Contact Editions.

Bainbridge Cohen, B. (2018). Basic neurocellular patterns: Exploring developmental movement. El Sobrante, CA: Burchfield Rose.

Cairney, J., Kiez, T., Roetert, E.P., \& Kriellaars, D. (2019). A 20th-century narrative on the origins of the physical literacy construct. Journal of Teaching in Physical Education, 38(2), 79-83. doi:10.1123/jtpe. 2018-0072

Chodzko-Zajko, W. (2014). The American Kinesiology Association undergraduate core curriculum. Quest, 66(3), 288-294. doi:10. 1080/00336297.2014.918896

Davids, K., Button, C., \& Bennett, S. (2008). Dynamics of skill acquisition: A constraints-led approach. Champaign, IL: Human Kinetics.

Doidge, N. (2015). The brain's way of healing: Remarkable discoveries and recoveries from the frontiers of neuroplasticity. New York, NY: Viking.

Durden-Myers, E.J., Meloche, E.S., \& Dhillon, K.K. (2020). The embodied nature of physical literacy: Interconnectedness of lived experience and meaning. Journal of Physical Education, Recreation and Dance, 91(3), 8-16. doi:10.1080/07303084.2019.1705213

Eddy, M. (2009). A brief history of somatic practices and dance: Historical development of the field of somatic education and its relationship to dance. Journal of Dance and Somatic Practices, 1(1), 5-27. doi:10. 1386/jdsp.1.1.5_1

Edwards, L.C., Bryant, A.S., Keegan, R.J., Morgan, K., \& Jones, A.M. (2017). Definitions, foundations and associations of physical literacy: A systematic review. Sports Medicine, 47(1), 113-126. PubMed ID: 27365029 doi:10.1007/s40279-016-0560-7

Hanna, T. (1970). Bodies in revolt: A primer in somatic thinking. New York, NY: Holt, Rinehart and Winston.

Hanna, T. (1988). Somatics: Reawakening the mind's control of movement, flexibility, and health. Reading, MA: Addison-Wesley.

Henry, F. (1964). Physical education: An academic discipline. Journal of Health, Physical Education, and Recreation, 35(7), 32-69. doi:10. 1080/00221473.1964.10621849

Johnson, T.G., \& Twietmeyer, G. (2018). The necessity of physical activity in kinesiology degree programs. Journal of Physical Education, Recreation, and Dance, 89(2), 42-48. doi:10.1080/07303084. 2017.1404513

Juhan, D. (2003). Job's body: A handbook for bodywork (3rd ed.). Barrytown, NY: Station Hill Press.

Keegan, R.J., Barnett, L.M., Dudley, D.A., Telford, R.D., Lubans, D.R., Bryant, A.S., .. V Vella, S.A. (2019). Defining physical literacy for application in Australia: A modified delphi method. Journal of Teaching in Physical Education, 38(2), 105-118. doi:10.1123/jtpe. 2018-0264.

Kelso, J.A.S. (1995). Dynamic patterns: The self-organization of brain and behavior. Cambridge, MA: MIT Press.
Kontra, C., Lyons, D.J., Fischer, S.M., \& Beilock, S.L. (2015). Physical experience enhances science learning. Psychological Science, 26(6), 737-749. PubMed ID: 25911125 doi:10.1177/0956797615569355

Kugler, P.N., \& Turvey, M.T. (1987). Information, natural law, and the selfassembly of rhythmic movement. Hillsdale, NJ: Lawrence Erlbaum.

Kuhn, T.S. (1970). The structure of scientific revolutions (2nd ed.). Chicago, IL: University of Chicago Press.

Menakem, R. (2017). My grandmother's hands: Racialized trauma and the pathway to mending our hearts and bodies. Las Vegas, NV: Central Recovery Press.

Montessori, M. (1967). The absorbent mind. New York, NY: Holt, Rinehart and Winston.

Myers, T.W. (1998). Kinesthetic dystonia: What bodywork can offer a new physical education. Journal of Bodywork and Movement Therapies, 2(2), 101-114. doi:10.1016/S1360-8592(98)80031-4

National Center for Complementary and Integrative Health. (2018). Health information - complementary, alternative, or integrative health: What's in a name? [Web page]. https://www.nccih.nih.gov/health/ complementary-alternative-or-integrative-health-whats-in-a-name

Newell, K.M. (1990). Physical activity, knowledge types, and degree programs. Quest, 42(3), 243-268.

Piaget, J. (1952). The origins of intelligence in children. New York, NY: International Universities Press.

Plakun, E.M. (2020). The mental health crisis in America: Recognizing problems; working toward solutions: Part 1. Defining the crisis. Journal of Psychiatric Practice, 26(1), 52-57. PubMed ID: 31913970 doi: $10.1097 /$ pra.0000000000000438

Polanyi, M. (1962). Personal knowledge: Towards a post-critical philosophy. Chicago, IL: University of Chicago Press.

Polanyi, M. (1966). The tacit dimension. Chicago, IL: University of Chicago Press.

Salmon, P. (2020). Mindful movement in psychotherapy. New York, NY: Guilford Press.

Sheets-Johnstone, M. (1999). The primacy of movement. Amsterdam, the Netherlands: Benjamins.

Sherrington, C. (1951). Man on his nature. Cambridge, UK: The University Press.

Shortt, C.A., Webster, C.A., Keegan, R.J., Egan, C.A., \& Brian, A.S. (2019). Operationally conceptualizing physical literacy: Results of a Delphi study. Journal of Teaching in Physical Education, 38(2), 91-104. doi:10.1123/jtpe.2018-0202

Sperry, R.W. (1952). Neurology and the mind-brain problem. American Scientist, 40(2), 291-311.

Stoffregen, T.A., \& Bardy, B.G. (2001). On specification and the senses. Behavioral and Brain Sciences, 24(2), 195-213. PubMed ID: 11530542 doi:10.1017/S0140525X01003946

Sweigard, L. (1974). Human movement potential: Its ideokinetic facilitation. New York, NY: Dodd-Mead.

Thelen, E. (2000). Grounded in the world: Developmental origins of the embodied mind. Infancy, 1(1), 3-28. PubMed ID: 32680313 doi:10. 1207/S15327078IN0101_02

Thelen, E. (2005). Dynamic systems theory and the complexity of change. Psychoanalytic Dialogues, 15(2), 255-283. doi:10.1080/ 10481881509348831

Thelen, E., \& Smith, L.B. (1994). A dynamic systems approach to the development of cognition and action. Cambridge, MA: MIT Press.

Thomas, J.R., Clark, J.E., Feltz, D.L., Kretchmar, R.S., Morrow, J.R., Reeve, T.G., \& Wade, M.G. (2007). The Academy promotes, unifies, and evaluates doctoral education in kinesiology. Quest, 59(1), 174194. doi:10.1080/00336297.2007.10483547

Todd, M.E. (1937). The thinking body: A study of the balancing forces of dynamic man. New York, NY: Paul B. Hoeber. 
Tomporowski, P.D., \& Pesce, C. (2019). Exercise, sports, and performance arts benefit cognition via a common process. Psychological Bulletin, 145(9), 929-951. PubMed ID: 31192623 doi:10.1037/bul0000200

Twietmeyer, G., \& Johnson, T.G. (2019). A kinesiology conundrum: Physical activity requirements in kinesiology degree programs. Quest, 71(1), 90-111. doi:10.1080/00336297.2018.1556709

Vygotsky, L.S. (1978). Mind in society: The development of higher psychological processes. Cambridge, MA: Harvard University Press.
Whitehead, M. (2001). The concept of physical literacy. European Journal of Physical Education, 6(2), 127-138. doi:10.1080/ 1740898010060205

Whitehead, M. (2013). Definition of physical literacy and clarification of related issues. ICSSPE Bulletin, 65, 29-34.

Wilson, M. (2002). Six views of embodied cognition. Psychonomic Bulletin \& Review, 9(4), 625-636. PubMed ID: 12613670 doi:10. 3758/BF03196322 